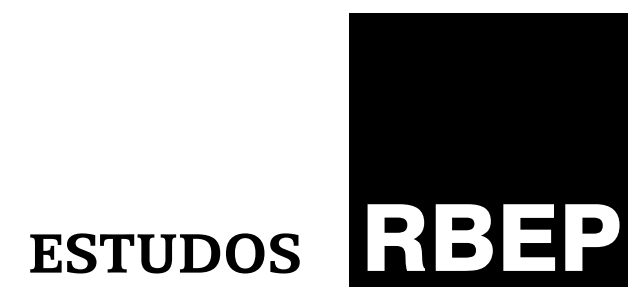

\title{
O subproduto social advindo das cotas raciais na educação superior do Brasil
}

Hélio Santos

Marcilene Garcia de Souza

Karen Sasaki

\section{Resumo}

Propõe demonstrar que as ações afirmativas no Brasil, no âmbito da universidade pública, originalmente reivindicadas pelo segmento negro, acabaram proporcionando um consistente subproduto social que beneficiou outros segmentos etnicorraciais. Para tanto, foi realizada uma análise de indicadores sobre a temática, com a qual pôde inferir as conclusões dos autores. Nesse sentido, o conceito de "subproduto social" deve ser entendido como a extensão de benefícios a outros grupos sociais que historicamente não sofreram desvantagens efetivas no Brasil. Trata-se de um artefato conceitual que possui dois componentes: o primeiro decorre da essência do debate ideológico sobre o tema e o outro tem um cunho perverso, pois transfere as vagas das "cotas raciais" não preenchidas para as "cotas sociais".

Palavras-chave: ação afirmativa; educação superior pública; cotas raciais; cotas sociais. 


\section{Abstract \\ Social by products from Brazilian higher education quota system}

The aim of this study is to present that affirmative actions in Brazilian public universities, which were originally claimed by the Black movement, ended up developing benefits to other social, racial and ethnic groups. Thus, we performed an analysis of indicators in order to infer the authors' conclusions. Therefore, the concept of "social by products" must be understood as the extension of benefits to other social groups that have not historically suffered significant disadvantages in Brazil. This is a conceptual discussion about two components: the first one is the essence of the ideological debate on the subject and the other is a perverse nature, because it moves vacancies from "racial quotas" to "social quotas".

Keywords: affirmative action; higher public education; racial quotas; social quotas.

\section{Introdução}

O principal objetivo deste artigo é demonstrar que as ações afirmativas no Brasil, originalmente reivindicadas pelo segmento negro, acabaram proporcionando um consistente subproduto social que beneficiou outros segmentos etnicorraciais no âmbito da universidade pública. Para atingir o objetivo colimado, é necessário preliminarmente evidenciar como as políticas afirmativas surgem no Brasil e em qual contexto elas se desenvolvem.

Para tanto, foram selecionados textos que cobrem a temática no período de aproximadamente 15 anos, desde o início do debate daquela iniciativa no País em meados da década de 1990. Em seguida, com base no trabalho denominado Mapa das ações afirmativas: instituições públicas de ensino superior, desenvolvido pelo Instituto Nacional de Ciência e Tecnologia e Inclusão no Ensino Superior e na Pesquisa (INCT Inclusão), foi feita uma análise do quadro das instituições de ensino que desenvolveram algum tipo de ação afirmativa (Brasil. INCT Inclusão, 2012). Tal análise permitiu demonstrar a forma como os diversos grupos vêm usufruindo os benefícios dessa política. Para aprofundar a discussão, ainda foram examinados dois tipos de indicadores: um de cunho abrangente, oriundo do Censo da Educação Superior do Ministério da Educação (MEC), e outro com foco mais particularizado, referente a uma universidade pública localizada na Região Sul do País. O conjunto do trabalho busca demonstrar como as cotas raciais estão gerando subprodutos sociais para outros grupos.

A ideia de tratar a todos igualmente no Brasil encarna um tipo de isonomia cega, que não atende à efetiva desigualdade estrutural que atinge determinados segmentos. Assim, a justificativa dos que apoiam 
as ações afirmativas é de que nada é mais desigual do que tratar a todos igualmente. Vê-se que as políticas afirmativas no Brasil nascem desse entendimento.

As políticas de ação afirmativa no âmbito da educação superior aqui no Brasil apelidadas de "cotas" - acabam de completar dez anos de prática ininterrupta. Em 2011, cerca de 125 instituições públicas de ensino adotaram algum tipo de ação afirmativa para o acesso aos seus cursos (Brasil. INCT Inclusão, 2012). O tempo percorrido até hoje e a magnitude dos números justificam este artigo, que visa analisar uma política pública que rompe com um caminho universalista caro à intelligentsia brasileira.

Para a consecução do presente artigo, requer-se deslindar algumas questões: 1) As políticas de ação afirmativa implementadas na área educacional do País são decorrentes da reivindicação de qual grupo social? 2) Atualmente, quais são os grupos etnicorraciais atendidos pelas ações afirmativas? 3) De que forma e em qual magnitude esses grupos são atendidos?

\section{As ações afirmativas}

A expressão ação afirmativa (affirmartive action) é reconhecida como uma criação do governo Kennedy em 1963, ao se referir à necessidade de promover a igualdade de oportunidades no emprego para negros e brancos nos Estados Unidos (Walters, 1997, p. 106).

As políticas de ação afirmativa são uma iniciativa "cujo objetivo principal é adotar medidas que reparem e compensem os grupos que sofreram no passado perdas em razão de abusos de quaisquer tipos" (Santos, 2003, p. 336). Tais perdas decorreriam de exploração, discriminação, violência, preterimento e outros tratamentos degradantes.

O estudo de Souza (2010, p. 123) reitera que, apesar de o debate acerca das ações afirmativas, recentemente, ter-se tornado mais público nos meios de comunicação e nas universidades no Brasil, o tema não é novo no mundo. Essa prática tem sido considerada como um experimento ousado e "revolucionário" do direito no século 20 (Gomes, 2001, p. 8), quando se observam os impactos sociais, políticos, pedagógicos, psicológicos e históricos no que se refere ao combate das desigualdades.

Segundo a posição de diversos juristas, como Piovesan (2005), Silva Jr. (2002) e Gomes (2001), a "neutralidade estatal" tem se traduzido em fracasso, sobretudo em sociedades com o perfil do Brasil, em que, por muitos séculos, se manteve a subjugação formal de inferioridade legitimada pela lei, como no caso da escravização. Tal percepção atenta para a constatação de que:

[...] observando que somente a proibição da discriminação não tem surtido o efeito esperado no que diz respeito à sua eficácia, é necessário ao Estado "renunciar a seu histórico de neutralidade" em questões sociais, devendo assumir, ao contrário, uma posição ativa, até mesmo radical se vista à luz dos princípios norteadores da sociedade liberal clássica. (Gomes, 2001, p. 37). 
Ou seja, somente proibir a discriminação não é suficiente para garantir igualdade de tratamento dentro da diferença. É preciso promover o grupo discriminado, considerando a diversidade e o pluralismo, para que essas ações possam provocar "mudanças na mentalidade dos indivíduos na sociedade, condicionados pela tradição, pelos costumes e pela história" (Gomes, 2001, p. 44). Nesse sentido, o autor citado aponta os possíveis ganhos para a sociedade quando essas ações se tornam eficazes para induzir transformações culturais, pedagógicas e psicológicas no imaginário coletivo. Gomes (2001, p. 44) acentua ainda que esses efeitos persistentes (psicológicos, culturais e comportamentais) da discriminação do passado tendem a se perpetuar, resultando na chamada "discriminação estrutural".

Na mesma linha de entendimento, Santos (2003) destaca como a valorização da diversidade etnicorracial pode acarretar ganhos para o desenvolvimento do Brasil. Segundo esse autor, ao não se oferecer oportunidades efetivas na educação e emprego para certos segmentos discriminados da população, ocasionam-se perdas estruturais graves para o País como um todo (Santos, 2003, p. 346-347).

Entende-se que, se etnia e raça foram utilizadas para excluir, necessitam ser utilizadas também como critérios para incluir:

(...) temos o direito a ser iguais quando a nossa diferença nos inferioriza, e temos o direito a ser diferentes quando a nossa igualdade nos descaracteriza. Daí a necessidade de uma igualdade que reconheça as diferenças e de uma diferença que não produza, alimente ou reproduza as desigualdades. (Santos, 1999, p. 56).

É relevante atentar para alguns consensos construídos acerca da política afirmativa para negros (pretos e pardos) no ensino superior. Uma delas resulta na ideia de que os negros ascenderiam por meios artificiais, o que neutralizaria seus efeitos de modelo social, pois os negros socialmente bem-sucedidos seriam vistos como "indivíduos ajudados". No entanto, essa crítica insiste em erros, supondo que o sucesso das populações não negras é algo naturalmente conquistado. Vale dizer, não leva em conta que historicamente a discriminação contra os negros vem ajudando a reduzir a concorrência ante a posição que os brancos têm, traduzindo-se numa política artificial que os favorece (Sell, 2002, p. 28). Como se vê, trata-se de um sofisma que alega o mérito como doutrina, mas que não afere o que seria esse mérito caso as condições de disputa fossem efetivamente iguais.

Para Souza Neto (2008, p. 43), as políticas de ação afirmativa em nada destoam das premissas do Estado de bem-estar social, pois não alteram os pressupostos dessa ideia. Basta reconhecer que a discriminação racial e o racismo operam "produzindo um grau razoável de desigualdades; que as políticas públicas de natureza exclusivamente universal não têm contribuído efetivamente para diminuir essas desigualdades [...]", assim, as ações afirmativas não seriam propriamente "inovações", mas medidas especiais de promoção da igualdade. 


\section{Desigualdades sociorraciais no Brasil}

Quando no Brasil, por um lado, o Estado reconhece a necessidade de intervir, mediante políticas adequadas para corrigir graves distorções geradas pelo mercado e/ou pelas desigualdades de oportunidades, nota-se, por outro lado, a ideia de que cada indivíduo deve estar em condições de resolver suas próprias necessidades, com base no mérito de seu trabalho e na sua capacidade pessoal (Souza, 2010, p. 114).

A partir desses pressupostos contraditórios, pretende-se realçar como as políticas sociais universalistas foram ineficientes no que diz respeito à eliminação das desigualdades raciais. No decorrer da história social brasileira, persistiu uma notória fragilidade no sentido de possibilitar o mesmo tipo de acesso aos direitos sociais para determinados segmentos populacionais. Ou melhor, mesmo ao se reconhecer a discriminação racial como uma das mais evidentes expressões de acesso desigual aos recursos no Brasil, permanece o entendimento dúbio quanto à tomada de iniciativas para a alteração desse quadro em que se evidencia a vulnerabilidade social e econômica de cerca de metade da população:

Em termos materiais, na ausência de discriminações raciais institucionalizadas, esse tipo de racismo se reproduz pelo jogo contraditório entre uma cidadania definida, por um lado, de modo amplo e garantia por direitos formais, e por outro, uma cidadania cujos direitos são, em geral, ignorados, não cumpridos e estruturalmente limitados pela pobreza e pela violência cotidiana. O racismo se perpetua por meio de restrições factuais da cidadania, por meio de imposição de distâncias sociais criadas por diferenças enormes de renda e de educação, por meio de desigualdades sociais que separam brancos de negros. (Guimarães, 1999, p. 56).

Nesse sentido, o que se observa é que as políticas públicas não alcançaram sucesso no que diz respeito ao atendimento à população negra no Brasil, quando comparada à população branca (Pnud, 2005, p. 59).

A questão racial, de acordo com Ianni (2002, 2004), modifica-se ao acaso das situações, das formas de sociabilidade e dos jogos das forças sociais; reitera-se continuamente modificada, mas persistente. Esse é o enigma com o qual se defrontam uns e outros, intolerantes e tolerantes, discriminados e preconceituosos, segregados e arrogantes, subordinados e dominantes, em todo o mundo. Mais do que isso, a questão racial, para o autor, revela "como funciona a fábrica de sociedade, compreendendo identidade e alteridade, diversidade e desigualdade, cooperação e hierarquização, dominação e alienação" (Ianni, 2004, p. 45).

Nos anos 1950, a Organização das Nações Unidas para a Educação, a Ciência e a Cultura (Unesco) patrocinou pesquisas feitas por intelectuais como Florestan Fernandes, Roger Bastide, Oracy Nogueira e Thales de Azevedo sobre a temática racial. Algumas das impressões observadas por esses autores ratificaram aspectos da discriminação contra os negros já denunciados pela Frente Negra Brasileira na década de 1930. Essas pesquisas tornaram-se clássicas e até hoje confirmam que o Brasil 
não escapa à estratificação social por raça, ou seja, a pele mais escura significava em geral status social mais baixo (Bento, 2002, Nogueira, 1998, Skidmore, 1992).

Portanto, a mobilidade dos indivíduos atende a certa hierarquização destes, considerando, principalmente, a cor: quanto mais próximos do perfil "caucasoide", mais valor e mobilidade tendem a alcançar; e quanto mais próximos do perfil "negroide", menos mobilidade, na horizontal e na vertical. Ao mesmo tempo que se detecta o preconceito dado, observa-se como as relações raciais no Brasil estão marcadas pelas ideias de "igualitarismo racial" e de "miscigenação" (Nogueira, 1998, p. 201).

Ao enfrentar esse quadro sofisticado em que se pauta a questão racial - apontado por Nogueira (1998) -, Munanga (2007) e Moore (2007) convergem para uma posição que reforça aquele entendimento da hierarquização, ao defenderem a tese de que o racismo não se estrutura em torno do conceito biológico de raça, mas sim a partir de um dado universal inegável, o fenótipo.

Ao analisar as desigualdades raciais no Brasil, Paixão (2006) considera inaceitável que o modelo de desenvolvimento do País leve em conta apenas as variáveis econômicas vinculadas ao Produto Interno Bruto (PIB). Para o autor, é fundamental que se considere também a distribuição da riqueza produzida a partir da variável raça/cor (Paixão, 2006, p. 46).

O Relatório anual das desigualdades raciais no Brasil, organizado por Paixão et al. (2011), encontra-se já em sua segunda edição. O primeiro referiu-se aos anos 2007 e 2008 e o segundo, aos anos 2009 e 2010. Trata-se de um pormenorizado estudo no qual, em seis tópicos, se podem constatar as desigualdades raciais que persistem no Brasil do século 21. São eles: 1) padrões de morbimortalidade e acesso ao sistema de saúde; 2) saúde sexual e reprodutiva; 3 ) assistência social, segurança alimentar e nutricional; 4) acesso à previdência social, 5) acesso ao sistema de ensino e indicadores de proficiência; e 6) vitimização, acesso à justiça e políticas de promoção da igualdade racial (Paixão et al., 2011, p. 7-10).

Além desse consistente diagnóstico, há duas publicações que evidenciam as desigualdades raciais de maneira exemplar: a do Instituto de Economia Aplicada (Ipea), organizada por Mário Theodoro (2008), e a do Programa das Nações Unidas para o Desenvolvimento (Pnud) de 2005.

Tais indicadores apontam ao Estado brasileiro a necessidade de ações concretas focalizadas no desenvolvimento tendo como referência a questão etnicorracial.

\section{Contextualização política e histórica da ação afirmativa no Brasil}

No Brasil, a marcha organizada pelo Movimento Social Negro, realizada em 20 de novembro de 1995 em Brasília, pela comemoração do tricentenário de Zumbi dos Palmares, reivindicava do Estado ações efetivas para a redução das desigualdades raciais. Essa era a postura da militância nos meados da década de 1990. 
Nesse contexto, o governo federal, ao instalar no Ministério da Justiça (MJ), em 1996, o Grupo de Trabalho Interministerial de Valorização da População Negra (GTI População Negra), reconheceu que ações específicas deveriam ser tomadas no sentido de potencializar o segmento negro. Esse colegiado era formado por dez representantes de diversos ministérios e por oito membros advindos da sociedade civil - todas as pessoas desse segundo grupo eram negras (Jaccoud; Beghin, 2002, p. 14). O GTI População Negra elaborou um dos primeiros conceitos de ação afirmativa no País e, segundo as autoras citadas, foi largamente adotado:

Ações afirmativas são medidas especiais e temporárias, tomadas pelo Estado e/ou pela iniciativa privada, espontânea ou compulsoriamente, com o objetivo de eliminar desigualdades historicamente acumuladas, garantindo a igualdade de oportunidade e tratamento, bem como de compensar perdas provocadas pela discriminação e marginalização, por motivos raciais, étnicos, religiosos, de gênero e outros. (Brasil. MJ. SEDH, 1996, p. 10).

Esse conceito evidencia que a ação afirmativa é uma medida atual que visa a atacar os efeitos, no presente, da discriminação ocorrida no passado.

O que demarcou o início da discussão sobre as ações afirmativas no Brasil foi o seminário internacional "Multiculturalismo e Racismo: o papel da ação afirmativa nos Estados democráticos contemporâneos", realizado em julho de 1996, em Brasília, pelo Ministério da Justiça, quando especialistas e estudiosos estrangeiros e brasileiros apresentaram e debateram o tema (Jaccoud, 2009, p. 34).

Foi a partir daí que a agenda nacional abriu espaço para esse debate pioneiro. Desde então, a imprensa começou a se movimentar em torno do inusitado assunto para a sociedade brasileira. As ações afirmativas passaram a ser apelidadas pela imprensa de "cotas", quando essa expressão sinaliza uma metodologia. Como ensina Skidmore (1997, p. 130), as cotas apenas percentualizam metas e constituem uma maneira de trabalhar essa política de preferência adotada pela ação afirmativa.

O inusitado da reivindicação do movimento social negro, que propunha uma "discriminação positiva", surpreendeu a sociedade como um todo desde o início. A justiça e a imprensa em particular solaparam o que se convencionou chamar, na época, "racismo às avessas". Houve a partir de então a defesa intransigente de uma isonomia cega, que prega a igualdade de tratamento, inclusive para os desiguais.

A força dessa reação contrária surpreendeu parte das lideranças negras, o que a rigor não deveria ter ocorrido, em virtude de esses ativistas conhecerem bem a perversão dos efeitos culturais da "democracia racial" brasileira, cuja eficácia minou por todo um século qualquer iniciativa no pós-abolição, no sentido de se construir uma cidadania negra efetiva no País (Santos, 2003, p. 173-174).

Guimarães (1997) foi um dos primeiros autores a combater algumas falácias esgrimidas pelos adversários das ações afirmativas para a população negra, lembrando que a sociedade brasileira já experimentara 
com algum sucesso experiências de discriminação positiva, como a "Lei dos dois terços" do período Vargas (Lei no 7.967/1945). Tratava-se de uma cota que obrigava as empresas a reservar pelo menos dois terços de suas vagas para trabalhadores brasileiros, o que defendeu a mão de obra nacional por mais de duas décadas, numa época de franca preferência por profissionais estrangeiros. Para o autor citado, o equívoco da "falácia do mérito" - argumento central trazido pelos que combatiam as cotas raciais - está no fato de que "a ação afirmativa não dispensa, mas, ao contrário, exige uma política universalista de equidade de oportunidades" (Guimarães, 1997, p. 236), em virtude de essa prática só operar limitada a um determinado âmbito. Ou seja, os cotistas raciais disputam de maneira aguerrida e consistente suas vagas para a universidade pública, buscando seu espaço entre aqueles com os quais estão em igualdade efetiva de condições para competir.

Pelo sistema convencional do exame vestibular há um simulacro de aferição do mérito, no qual grupos que acumularam vantagens de todos os tipos (psicológicas, físicas, econômicas, educacionais e étnicas) disputam com pessoas em franca desvantagem. Por esse sistema, partes substanciais dos talentos do País "vazam pelo imenso ralo da falta de oportunidades" (Santos, 2008, p. 88).

Logo após a realização do seminário internacional que demarcou as ações afirmativas, o jornal Folha de S. Paulo publicou um debate, em que formulou uma questão a respeito da temática e convidou especialistas para respondê-la. Tradicionalmente aos sábados, há mais de uma década, a seção de opinião do citado jornal traz artigos com pontos de vista diferentes que respondem a uma pergunta sobre determinado tema. Cada um dos articulistas explica sua opção por uma das respostas possíveis: "não", "em termos" e "sim". A pergunta feita foi: O preconceito contra minorias deve ser enfrentado com políticas compensatórias (ações afirmativas)?

Assim, selecionou-se um trecho das diferentes posições acerca da pergunta feita aos especialistas, em que cada um enfatiza a sua opção. Ives Gandra da Silva Martins - advogado tributarista e professor emérito da Universidade Mackenzie -, que optou pela resposta "não", argumenta:

Não me convenço de que as políticas compensatórias para minorias "teoricamente" discriminadas sejam a solução. De início, porque ferem o princípio da isonomia plasmado na Constituição de que todos são iguais perante a lei. (Santos et al., 1996, p. 3).

Alayde Sant'Anna e Jessé Souza - secretária e diretor, respectivamente, da Secretaria dos Direitos da Cidadania do Ministério da Justiça, na época - também justificaram sua opção "em termos":

A implementação de ações afirmativas provoca discussões acirradas. Afinal, é o próprio princípio fundamental da democracia moderna, o da universalidade e igualdade formal, o qual deforma-se de forma perversa em um contexto que mascara desigualdades, que está em risco. Como a sua efetividade na realidade é baixa, faz-se necessário, pensam seus 
defensores, uma compensação legal para a ausência de igualdade ao nível da vida cotidiana real das pessoas. (Santos et al., 1996, p. 3).

Finalmente, Hélio Santos, coordenador do GTI, explicou a opção "sim" para a sua resposta:

Tratar de maneira igual pessoas que são atávica e secularmente diferentes é operar com um sofisma - porque simula um caminho democrático. Portanto, devemos adotar no Brasil algum tipo de política de ação afirmativa - cujo fim é criar uma sociedade democrática substantiva e não teórica. (Santos et al., 1996, p. 3).

Passados mais de 15 anos, sabe-se que essas posições ainda se mantêm para vários estudiosos. Todavia, é inegável que houve avanços desde então. O tema faz parte da agenda pública e inúmeras iniciativas foram tomadas, como será verificado a seguir.

Desde o seminário internacional ocorrido em Brasília em 1996, o qual demarcou o início do debate sobre as ações afirmativas para a população negra no País, nenhum fato foi mais relevante do que a decisão do Supremo Tribunal Federal (STF) tomada em 26 de abril de 2012. Por unanimidade, os ministros do STF consideraram constitucional o sistema de cotas raciais para o ingresso de alunos afrodescendentes em universidades públicas, em ação impetrada pelo Partido dos Democratas (DEM), em julho de 2009, contra a Universidade de Brasília (UnB), que desde 2004 adota o sistema de reserva de vagas para negros e indígenas (Brasil. STF, 2012). Para o impetrante, o sistema fere o princípio da igualdade e ofende dispositivos que estabelecem o direito universal à educação. Todavia, esse não foi o entendimento dos 11 juízes da suprema corte. O relator, ministro Ricardo Lewandowski, ao rejeitar o pedido do partido político, reconheceu a constitucionalidade das cotas raciais, no que foi acompanhado pelos outros dez ministros do STF.

O presidente do STF, ministro Ayres Brito, ao proclamar o resultado final, afirmou que "o Brasil tem mais um motivo para se olhar no espelho da história e não corar de vergonha" (Brasil. STF, 2012).

\section{As ações afirmativas como um subproduto social}

O que se evidencia é que coube ao Movimento Social Negro reivindicar as ações afirmativas para o ensino público no Brasil - tal iniciativa não foi de sindicatos, partidos políticos ou qualquer outro setor da sociedade civil. Carvalho (2005, p. 95), nesse sentido, enfatiza a "voz negra" reivindicando direitos educacionais desde os anos 1940, culminando com as ações de meados dos anos 1990:

Vale a pena recuperar também as propostas constantes do documento Por uma política de combate ao racismo e a desigualdade racial, entregue ao então Presidente da República Fernando Henrique Cardoso 
por ocasião da histórica Marcha Zumbi dos Palmares contra o Racismo, pela Cidadania e pela Vida, realizada no dia 20 de Novembro de 1995 em Brasília. O último item do Programa de Superação do Racismo na área de Educação demanda do Estado: "Desenvolvimento de Ações Afirmativas para o acesso dos negros aos cursos profissionalizantes, à universidade e às áreas de tecnologia de ponta".

Assim, a ideia de "subproduto social" que este artigo propõe é a de que a reivindicação de ações afirmativas específicas para a população negra - denominada genericamente "cotas raciais" - logrou beneficiar outros segmentos. Por outro lado, a cota destinada aos egressos das escolas públicas, quando não define os beneficiários específicos, como negros e/ ou indígenas, vem sendo denominada "cota social". Portanto, o conceito de "social" ficou preso ao fato de os beneficiários serem oriundos da rede pública de ensino, desvinculando as especificidades etnicorraciais.

É nesse sentido que o conceito de "subproduto social" deve ser entendido: as cotas nas universidades foram estendidas também para outros grupos que historicamente não sofreram desvantagens efetivas no Brasil.

Segundo Hansen e Mowen (2001, p. 227), no contexto industrial, um subproduto vem a ser um "produto secundário recuperado no decorrer da fabricação de um produto primário". Do ponto de vista deste artigo, o subproduto social é gerado num contexto de produção de políticas públicas específicas para afrodescendentes, mas que acabam por resultar benefícios a segmentos múltiplos da sociedade. Trata-se de um artefato que tem dois componentes objetivos: o primeiro ocorre quando a reivindicação das ações afirmativas para negros na educação faz surgir políticas de cotas para os demais estudantes vindos da rede pública de ensino - cota social. Nesse caso, as universidades operaram de duas formas: uma de cunho misto, em que há cota racial - para negros e/ou indígenas - e cota social; e a outra é a utilização pura e simples das cotas sociais destinadas a todos os estudantes - negros, indígenas, brancos, orientais -, para os quais a condição básica é que sejam originários da escola pública.

Esse primeiro componente do subproduto social é original, pois decorre da essência do debate ideológico que as ações afirmativas para negros suscitaram no País: se o problema é racial, têm-se políticas específicas. Por outro lado, pedem-se políticas mais generalistas se o problema for identificado apenas como social. Evidentemente, há quem opte pelas duas possibilidades: coexistem os problemas racial e social e ambos exigem uma política de reparação.

O segundo componente do subproduto social tem um cunho perverso, pois transfere as vagas das cotas raciais não preenchidas pelos candidatos negros para as cotas sociais que beneficiam os segmentos etnicorraciais que não acumularam déficit histórico de cidadania. O primeiro componente, original e ideológico, e o segundo, que transfere oportunidades, serão analisados e explicitados pelos dados apresentados a seguir. 


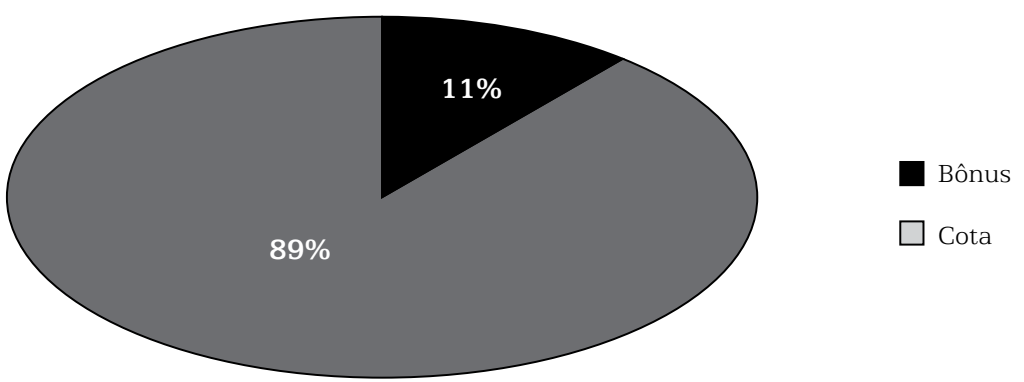

\section{Gráfico 1 - Tipo de Incentivo de Ação Afirmativa nas Universidades Públicas - Brasil - 2012}

Fonte: Brasil. INCT Inclusão. Mapa das ações afirmativas no Brasil. 2012. - Síntese dos autores.

Entre as 125 instituições de ensino que aderiram a programas de ação afirmativa, a expressiva maioria adota a metodologia de percentualizar a meta a ser alcançada - cotas. Cerca de 89\% das instituições (111) utilizam esse sistema e apenas 14 (11\%) concedem algum tipo de vantagem em que os candidatos recebem pontuação adicional no processo seletivo - bônus.

O Gráfico 2 revela que, da maioria dos estabelecimentos de ensino que aderiram aos programas de ações afirmativas, 82 entidades (66\%) são federais; 39 entidades (31\%) são estaduais; e apenas 4 instituições de ensino (3\%) são municipais. Vê-se que o setor estadual não aderiu com ênfase a um compromisso com as ações afirmativas, o que deixa evidente que para a implementação dessa política será necessária uma legislação específica de "cima para baixo", e não pelos conselhos universitários, como tem ocorrido com a maioria das instituições.

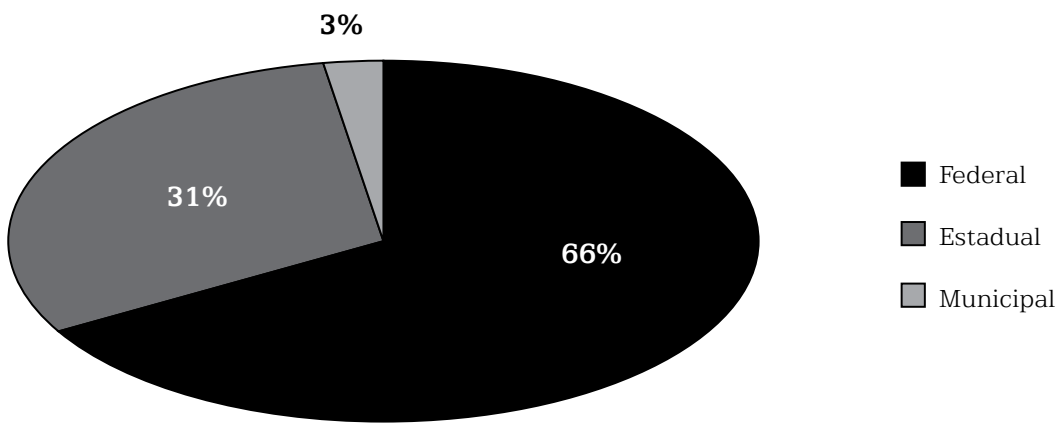

Gráfico 2 - Tipos de Instituição de Ensino Superior - Brasil

Fonte: Brasil. INCT Inclusão. Mapa das ações afirmativas no Brasil. 2012. - Síntese dos autores.

O Gráfico 3 traz as "cotas exclusivas", que vêm a ser a distribuição do atendimento das instituições de ensino às diversas categorias. São quatro as categorias atendidas com exclusividade: 1) negros e indígenas ("cotas raciais"); 2) alunos vindos da escola pública sem nenhum outro pré-requisito a não ser o de se originar desse tipo de estabelecimento de ensino ("cotas sociais"); 3) alunos que fazem parte de múltiplas combinações (etnicorraciais, sociais, regionais, pessoas com deficiência e baixa renda); 4) pessoas com deficiência, exclusivamente. 


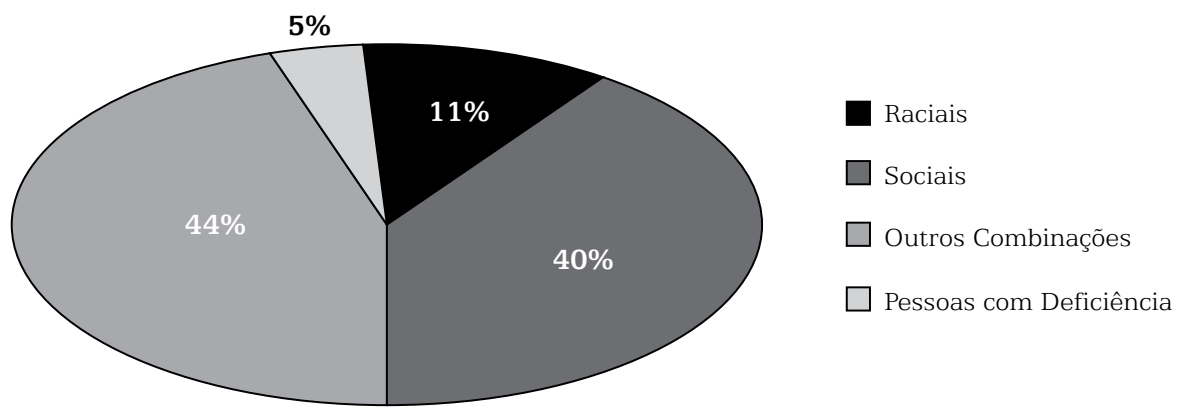

Gráfico 3 - "Cotas Exclusivas" nas Instituições Públicas - Brasil - 2012

Fonte: Brasil. INCT Inclusão. Mapa das ações afirmativas no Brasil. 2012. - Síntese dos autores.

Apenas cinco instituições têm cotas raciais, em que negros e indígenas são os únicos beneficiários: Universidade de Brasília (UnB); Universidade do Estado do Mato Grosso (Unemat); Universidade Estadual do Maranhão (Uema); Universidade Estadual de Mato Grosso do Sul (UEMS) e Universidade Federal de São Paulo (Unifesp). Outras nove instituições de ensino têm cotas exclusivamente para indígenas, sendo que nenhuma delas dispõe dessa política apenas para o segmento negro. No conjunto, as cotas raciais são praticadas por 14 instituições, o que perfaz apenas $11 \%$ do total delas. Constitui uma surpresa o fato de que nove daquelas instituições ofereçam cotas apenas para os indígenas em virtude da consolidada resistência ao critério etnicorracial exclusivo como acesso à universidade. Contudo, o tamanho da população indígena e a regionalidade do grupo parecem explicar parte do fenômeno, já que as instituições que atendem a essa exclusividade estão localizadas em espaços em que há maior presença daquele segmento étnico.

Entre as cotas exclusivas, destaca-se a preferência das instituições de ensino pelas cotas sociais, em que cerca de 40\% delas (50 entidades) optam por atender a todos os segmentos étnicos, desde que venham da escola pública. Porém, 44\% das instituições - 55 ao todo - se enquadram no grupo "outras combinações", em que se mesclam cotas que levam em conta aspectos etnicorraciais e/ou sociais, regionais e outros para o acesso ao ensino superior. Destaca-se ainda o fato de seis instituições (5\%) oferecerem cotas exclusivamente para pessoas com deficiência, não estendendo essa política a nenhum outro segmento.

O Gráfico 3 permite flagrar como o subproduto social, em seu componente ideológico, é significativo. Apesar da original e contundente reivindicação das ações afirmativas para os negros pelo movimento social, nenhuma das 125 instituições de ensino propicia cotas exclusivas para esse segmento. Grande parte das instituições de ensino superior da área pública, ao instituir as cotas, opta por uma seleção não focada no critério etnicorracial. Evidencia-se o entendimento de que a questão do não acesso ao ensino superior público no Brasil é de cunho social e não etnicorracial. Assim, ao reivindicar as cotas raciais para o segmento negro, acabou-se por implementar as chamadas cotas sociais que até então inexistiam no País. 


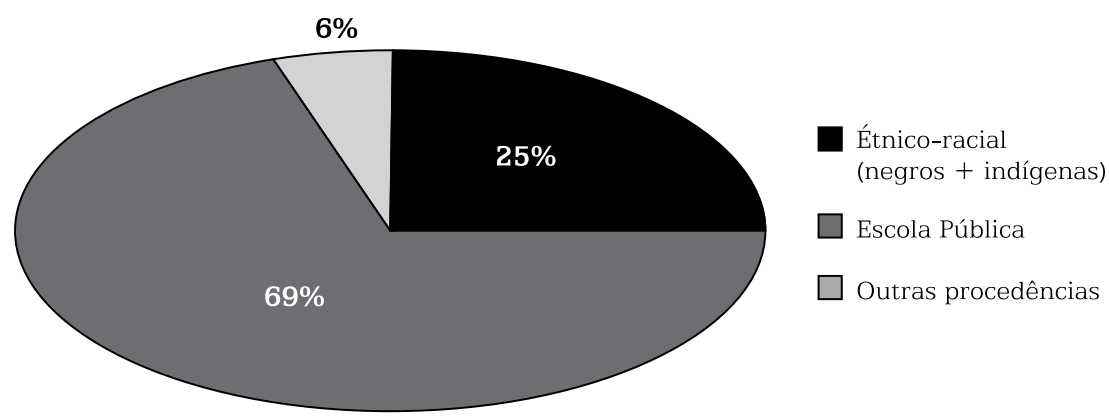

Gráfico 4 - Distribuição de Ações Afirmativas via IES Públicas - Brasil - 2009

Fonte: Brasil. Inep. Censo Educação Superior. 2009.

O Gráfico 4 permite reforçar a análise feita no tópico anterior. Tem-se agora a informação do Censo da Educação Superior de 2009, no qual se constata que 69\% dos beneficiários matriculados nas instituições públicas com o apoio de algum tipo de ação afirmativa são provenientes do critério social. Apenas um quarto dos matriculados é oriundo de uma seleção que leva em conta o critério etnicorracial, em que negros e/ou indígenas são os beneficiários; restando ainda $6 \%$ de alunos vindos de outras procedências. Vê-se aqui não os critérios das instituições, mas sim o número de beneficiados alcançados. Mais de dois terços dos beneficiários das ações afirmativas proporcionadas pelo ensino superior público são admitidos por critérios em que a variável etnicorracial não é considerada.

Hansen e Mowen (2001), ao se referirem à produção industrial, advertem que a inovação tecnológica e a introdução de novos métodos de fabricação podem tornar o subproduto de hoje no principal produto de amanhã. Trazem como exemplo a serragem e as lascas de madeira, que, de subprodutos das serrarias, se tornaram matéria-prima valiosa como componentes de madeira aglomerada de alto valor agregado (Hansen; Mowen, 2001, p. 228).

Os dados do Gráfico 4 revelam que essa possibilidade aventada pelos autores citados pode adaptar-se com perfeição ao contexto das políticas públicas do País: o principal produto das ações afirmativas hoje no Brasil são as cotas sociais, ou seja, a reivindicação de uma ação afirmativa de cunho etnicorracial - que era o produto almejado a princípio - acabou proporcionando mais de $2 / 3$ (69\%) das vagas preenchidas a um critério diferente do proposto; fenômeno que neste artigo foi denominado subproduto social das cotas raciais.

O subproduto social das cotas raciais tem como pano de fundo uma questão de cunho ideológico: o que dificulta o acesso democrático à instituição pública de ensino superior é a condição social dos candidatos, contrariando a tese do movimento social negro que tem na história racial do indivíduo a marca que justifica a ação afirmativa. A rigor, cabe questionar se essa "cota social" deveria ser considerada uma política de ação afirmativa, a qual conceitualmente requer a existência de desigualdades históricas acumuladas contra aqueles que devem se beneficiar da iniciativa. 
Os dados da Tabela 1 demonstram que, além do subproduto social de cunho ideológico, há outros aspectos a serem considerados nessa construção conceitual.

Tabela 1 - Amostra de Dados Relativos aos Vestibulares da Universidade Federal do Paraná (UFPR) - 2008-2010

\begin{tabular}{|l|r|r|r|}
\hline \multicolumn{1}{|c|}{ Ano/Vestibular } & \multicolumn{1}{c|}{2008} & \multicolumn{1}{c|}{2009} & \multicolumn{1}{c|}{2010} \\
\hline Vagas ofertadas & $5.204(1)$ & $5.334(2)$ & 5.540 (3) \\
\hline 20\% cotistas raciais & 1.041 & 1.067 & 1.108 \\
\hline Cotistas aprovados (4) & 321 & 377 & 432 \\
\hline Vagas não aproveitadas pelas cotas raciais & 720 & 690 & 676 \\
\hline Percentual do "Subproduto social" & $69 \%$ & $65 \%$ & $61 \%$ \\
\hline Fontes: (1) www.ufpr.br; (2) www.bemparana.com.br; (3) www.gazetamaringa.com.br; (4) Marçal, 2011
\end{tabular}

- Síntese dos autores.

A Tabela 1 é oriunda de diversas fontes e refere-se aos dados dos vestibulares de 2008, 2009 e 2010 da Universidade Federal do Paraná (UFPR), que adota política de cotas para negros e para a rede pública desde 2004, reservando 20\% das vagas para cada um desses segmentos. A análise dos dados da UFPR permite avaliar o segundo tipo de componente do subproduto social das cotas raciais: o de "transferência de oportunidades".

A tabela revela as dificuldades estruturais do segmento negro no campo da Educação (Santos, 2003, p. 85), que não tem conseguido absorver toda a meta que lhe foi reservada, perdendo parte significativa de suas oportunidades. Nota-se a expressividade das vagas não aproveitadas pelas cotas raciais na Tabela 1. Essa análise foi feita a partir de dados levantados em uma dissertação de mestrado que teve acesso ao número de cotistas raciais efetivamente aproveitados naqueles vestibulares (Marçal, 2011). Contudo, não se tem informações específicas no que diz respeito aos cursos mais disputados, como Medicina, Odontologia, Direito e Engenharias.

Analisando-se os dados da UFPR, nota-se o seguinte: as vagas ofertadas vêm crescendo; consequentemente, os 20\% reservados aos negros também, mas persiste um aproveitamento inferior a $40 \%$ daquela meta institucional. Isso equivale a dizer que menos de $8 \%$ das vagas da UFPR vêm sendo preenchidas pelos cotistas negros, os quais têm na universidade uma meta de 20\% reservada para eles. Assim, cerca de $12 \%$ das vagas não preenchidas vão reforçar as cotas para a rede pública (cotas sociais), que de $20 \%$ saltam para $32 \%$ em 2010, perfazendo quase um terço do total das vagas.

Esse quadro vem tornando a UFPR uma oportunidade ímpar para os candidatos da rede pública. As 2.086 vagas não utilizadas pelos negros em 3 anos seguidos - 720 vagas em 2008, 690 em 2009 e 676 em 2010 - foram oportunidades perdidas que se transferiram para outros segmentos etnicorraciais. Trata-se de um subproduto social legítimo por 
"transferência", em que as cotas sociais são reforçadas pelas cotas raciais não aproveitadas.

É instigante observar que efeito similar foi notado por Walters (1997) nos Estados Unidos. Para esse autor, a Lei dos Direitos Civis de 1964 decorreu de uma movimentação "que visou quebrar as barreiras erguidas pelo sistema da supremacia branca" naquele país (Walters, 1997, p. 105). Entretanto, apesar desse foco racial original, as mulheres brancas, entre 1988 e 1993, ganharam 2 milhões de empregos em nível de gerência e, entre 1970 e 1993, sua participação na força de trabalho aumentou 15\%, duas vezes mais que a dos negros (Walters, 1997 p. 118). Sabe-se hoje que as ações afirmativas nos Estados Unidos beneficiaram significativamente mais as mulheres brancas. Trata-se de um contexto distinto do brasileiro, mas que revela um fenômeno perverso comum aos dois países no que diz respeito às políticas públicas destinadas aos negros.

As dificuldades estruturais observadas no Paraná, em que os estudantes negros não absorvem as vagas destinadas a eles, por certo não se restringem apenas àquele Estado de população de maioria branca. Cabe perguntar, então: Como deve estar ocorrendo em Estados como Maranhão e Bahia, onde a população negra é majoritária?

As principais universidades públicas desses dois Estados, respectivamente a Universidade Federal do Maranhão (UFMA) e a Universidade Federal da Bahia (UFBA) - ambas adotam cotas raciais -, não dispõem desse controle, ou seja, não se sabe exatamente dos níveis de aproveitamento das cotas pelos afrodescendentes tendo como referencial os percentuais preestabelecidos e nem se todos os cursos - o que inclui os mais disputados e valorizados - vêm absorvendo de maneira adequada e justa as vagas reservadas. Sabe-se que as dificuldades estruturais da população negra é uma realidade que abrange todo o território nacional - fato esse evidenciado pelos mais importantes censos que aferem a educação no País. O Índice de Desenvolvimento da Educação Básica (Ideb) de 2011 revelou que o aluno do ensino médio da escola pública tem menos conhecimento do que aquele que cursa o ensino fundamental na escola particular. Como é sabido, a maioria dos alunos do ensino médio que estudam na escola pública é negra. Paixão et al. (2011, p. 235), utilizando dados da Pesquisa Nacional por Amostra de Domicílios (Pnad) de 2008, demonstram que no País cerca de 56\% dos estudantes daquela escola são negros, por outro lado, no ensino médio da escola particular, os brancos somam cerca de $70 \%$ dos alunos.

Os diversos dados revelados neste artigo indicam que o controle da efetividade das ações afirmativas nas instituições públicas é ferramenta crucial para um país tão retardatário em medidas de inclusão educacional como o Brasil.

\section{Considerações finais}

Sabe-se hoje que 125 instituições públicas de ensino superior adotam algum tipo de política de ação afirmativa (Brasil. INCT Inclusão, 
2012), mas não se tem notícia sobre o controle dessas iniciativas. A simples ausência de um monitoramento - medida que não requer esforço extraordinário daquelas instituições, em vista de poder ser efetuada a partir das matrículas - diz muito a respeito da falta de importância dada às políticas de ação afirmativa no País.

A prestação de contas, a transparência e a fiscalização são da essência do regime republicano (Siraque, 2009 apud Souza 2010, p. 147). No entanto, em uma política tão reclamada e debatida como a das ações afirmativas, era de se esperar um maior cuidado por parte das autoridades acadêmicas. O controle é o que possibilita aperfeiçoar as políticas públicas dando a elas maior efetividade - objetivo caro ao Estado democrático de direito. As ações afirmativas no ensino superior público, em virtude de suas singularidades no Brasil, exigem cuidado e refinamento na produção de dados para possibilitar ao gestor acadêmico tomadas de decisão adequadas, a fim de não frustrar as expectativas que aquelas iniciativas guardam. Além da sociedade civil, a Secretaria Especial de Política de Promoção da Igualdade Racial (Seppir), que tem status de ministério, deveria monitorar as ações afirmativas implementadas para que essas políticas tenham efetividade.

A adoção majoritária do sistema de cotas sociais pelas instituições de ensino público no Brasil demonstra que, em larga medida, se entende que os diversos segmentos etnicorraciais não sofreram desvantagens que justifiquem um tratamento diferenciado. No que diz respeito aos indígenas, verificou-se que nove instituições atendem exclusivamente a eles, o que é bastante significativo considerando-se a saga desse segmento etnicorracial.

Parte considerável das instituições faz uso de um critério misto, que mescla cotas sociais com raciais, reconhecendo que além das desvantagens históricas dos negros, existem outras de cunho social para com aqueles que não podem pagar a escola do ensino básico particular. Por outro lado, prevalece um clamor da mídia contra as "cotas para negros", mas não contra as cotas sociais. Estas, como revelou o Gráfico 4, têm sido melhor assimiladas. Essa posição da imprensa se manteve após a histórica decisão de 12 de abril de 2012 do STF em relação à constitucionalidade das cotas de cunho racial.

Para se compreender tudo o que está em jogo em torno desse debate, é fundamental atinar para um dos principais filões do setor de serviços do País. Matéria de jornal trouxe o estudo do Instituto de Ensino e Pesquisa (Insper) em que se revela que o Brasil supera os países "ricos no gasto em escola privada", (Takahashi, 2011), desde o ensino fundamental aos cursos de pós-graduação. Foi revelado que as famílias gastam o equivalente a 1,3\% do PIB brasileiro em educação. Na Alemanha, gasta-se com a escola privada em torno de 0,7\% do PIB, o que demonstra que, em termos relativos, se despende aqui com a educação particular quase o dobro do que gasta aquele rico país europeu. A indústria que se consolidou no Brasil em torno dos cursos pré-vestibulares e da massificação do ensino superior privado é um dos setores que devem ser afetados pela política 
afirmativa nas universidades públicas. Assim, pode-se entender porque a Confederação Nacional dos Estabelecimentos de Ensino (Cofenen) entidade sindical que reúne as instituições de ensino privado no País - foi um dos primeiros setores a se posicionar, chegando a ajuizar junto ao STF uma Ação Direta de Inconstitucionalidade (ADI 3197) contra as cotas nas universidades estaduais do Rio de Janeiro, em 2004, a qual foi arquivada em março de 2012 (Brasil. STF, 2012a). A mesma entidade sindical se posicionou de novo - agora contra o Projeto de Lei da Câmara que regulamenta o sistema de cotas nas universidades federais (PLC 180/08), que foi aprovado pelo Senado e, em seguida, sancionado pela presidenta Dilma Rousseff em 29 de agosto de 2012. A iniciativa reserva metade das vagas para as cotas raciais e sociais (Lei $\mathrm{n}^{\circ} 12.711 / 2012$ ).

Para os que apoiam as ações afirmativas como forma de reduzir as desigualdades, antes de tudo, a decisão do STF favorável à constitucionalidade das cotas raciais proporcionou um ajuste moral da sociedade brasileira. Trata-se de uma atitude que abre possibilidades para um novo tipo de desenvolvimento que vem impregnado por um atributo inédito no País: o da sustentabilidade moral, que busca reduzir as abissais desigualdades de oportunidades oferecidas a brancos e negros. O Brasil será o que a população negra for. A consolidação do País - moderno, forte economicamente e justo ao mesmo tempo - dar-se-á por essa via, da sustentabilidade moral.

Por outro lado, não se deve perder de vista que o acesso à universidade sempre foi um fator relevante para a mobilidade socioeconômica das pessoas no Brasil e é, sobretudo por isso, que o tema das cotas ganha tanto espaço.

O conceito de "subproduto social" das cotas raciais abordado aqui deve ser entendido em sua dupla constituição: a de cunho ideológico e a de transferência de oportunidades. O somatório desses dois componentes fortaleceu as oportunidades dos estudantes do ensino básico da escola pública nessa década de ações afirmativas que se completou em 2011. Caberia discutir noutra ocasião outros tipos de componentes que, de certa forma, fortalecem também o contexto social. Trata-se dos ganhos individuais que as pessoas adquirem quando operam em grupos humanos mais heterogêneos e que são de cunho subjetivo. Tais ganhos não se confundem com os benefícios advindos da sinergia promovida pela diversidade, já que estes não são subjetivos e proporcionam adições à produtividade e ao desenvolvimento e também são outro tipo de subproduto trazido pelas ações afirmativas (Instituto Ethos, 2000, p. 28). Entretanto, este artigo buscou identificar a potencialização das oportunidades dos estudantes provenientes da rede pública de ensino. Como demonstrado, as cotas raciais proporcionaram e continuam alavancando as cotas sociais no País.

A história das populações negra e indígena no Brasil é vista por renomados estudiosos, por exemplo, Darcy Ribeiro, como um eterno doar. Foi assim por três séculos e meio de escravismo - o mais longo da escravidão colonial - e tem sido assim também na cultura que singulariza 
o Brasil e os brasileiros perante o resto do mundo (Ribeiro, 1987, 1996). O subproduto social focado neste artigo - em que as políticas afirmativas inicialmente apresentadas pelo movimento negro acabam por proporcionar mais oportunidades aos demais grupos - parece ser mais um exemplo tardio desse tipo de vocação. Não se cogitou de transferir essas oportunidades aos negros da classe média que estudam no ensino básico particular e que por isso não fazem jus às cotas raciais nem sociais oferecidas pela universidade pública, apesar de eles enfrentarem também o racismo em seu cotidiano.

O que este artigo ainda revela é que a ideia do social, no Brasil, em larga medida, exorcizou o ogro de cunho etnicorracial. Entende-se, assim, que a pobreza pasteuriza as desigualdades, quando a realidade aferida por reconhecidas instituições de pesquisa não avalizam esse entendimento.

\section{Referências bibliográficas}

BENTO, M. A. Silva. Branqueamento e branquitude no Brasil. In: CARONE, Iray; BENTO, Maria Aparecida Silva (Orgs.). Psicologia social do racismo: estudos sobre branquitude e branqueamento no Brasil. Petrópolis: Vozes, 2002.

BRASIL. Instituto Nacional de Ciência e Tecnologia e Inclusão no Ensino Superior e na Pesquisa (INCT Inclusão). Mapa das ações afirmativas: instituições públicas de ensino superior. Brasília, 2012. Disponível em: $<$ http://www.inctinclusao.com.br/acoes-afirmativas/mapa $>$.

BRASIL. Instituto Nacional de Estudos e Pesquisas Educacionais Anísio Teixeira (Inep). Censo da Educação Superior de 2009. Brasília, 2009.

BRASIL. Instituto Nacional de Estudos e Pesquisas Educacionais Anísio Teixeira (Inep). IDEB: Índice de Desenvolvimento da Educação Básica de 2011. Brasília, 2012.

BRASIL. Ministério da Justiça (MJ). Secretaria de Estado dos Direitos Humanos (SEDH). Relatório do Grupo de Trabalho Interministerial População Negra. Brasília, 1996.

BRASIL. Projeto de Lei da Câmara, no 180 de 2008. Dispõe sobre o ingresso nas universidades federais e estaduais e nas instituições federais de ensino técnico de nível médio e dá outras providências. Disponível em: < http://www.senado.gov.br/atividade/materia/detalhes. asp?p_cod_mate=88409>. Acesso em: 29 ago. 2012 . 
BRASIL. Supremo Tribunal Federal (STF). STF julga constitucional política de cotas na UnB. 2012. Disponível em: < http://www.stf.jus.br/ portal/cms/verNoticiaDetalhe.asp?idConteudo $=206042>$. Acesso em: 26 abr. 2012.

BRASIL. Supremo Tribunal Federal (STF). Arquivada ADI contra lei revogada sobre cotas no RJ. 2012a. Disponível em: < http://www.stf. jus.br/portal/cms/verNoticiaDetalhe.asp?idConteudo=203199>. Acesso em: 21 mar. 2012.

CARVALHO, José Jorge de. Inclusão étnica e racial no Brasil: a questão das cotas no ensino superior. São Paulo: Atlas, 2005.

GOMES, Joaquim Barbosa. Princípios constitucionais da igualdade: o direito como instrumento de transformação social, a experiência dos EUA. Rio de Janeiro: Renovar, 2001.

GUIMARÃES, Antônio Sérgio Alfredo. A desigualdade que anula a desigualdade: notas sobre a ação afirmativa no Brasil. In: SOUZA, Jessé (Org.). Multiculturalismo e racismo: uma comparação Brasil - Estados Unidos. Brasília: Ministério da Justiça, Secretaria Nacional de Direitos Humanos, 1997.

GUIMARÃES, Antônio Sérgio Alfredo. Racismo e anti-racismo no Brasil. São Paulo: Ed. 34, 1999.

HANSEN, Don; MOWEN, Maryanne. Gestão de custos: contabilidade e controle. São Paulo: Pioneira, 2001.

IANNI, Octávio. O pensamento social no Brasil. São Paulo: Edusc, Anpocs, 2004.

IANNI, Octávio. Tipos e mitos do pensamento brasileiro. Revista Brasileira de Ciências Sociais, São Paulo, v. 17, n. 49, jun. 2002.

INSTITUTO ETHOS DE EMPRESAS E RESPONSABILIDADE SOCIAL. Como as empresas podem (e devem) valorizar a diversidade. São Paulo: Instituto Ethos, 2000.

JACCOUD, Luciana (Org.). A construção de uma política de promoção da igualdade racial: uma análise dos últimos 20 anos. Brasília: IPEA, 2009.

JACCOUD, Luciana; BEGHIN, Nathalie. Um balanço da intervenção pública no enfrentamento das desigualdades raciais no Brasil. Brasília: IPEA, 2002. [Versão preliminar]. 
MARÇAL, José Antônio. Política de ação afirmativa na Universidade Federal do Paraná e a formação de intelectuais negros(as). 2011. 195 f. Dissertação (Mestrado em Educação) - Universidade Federal do Paraná, Curitiba, 2011.

MOORE, Carlos. Racismo e sociedade: novas bases epistemológicas para entender o racismo. Belo Horizonte: Mazza, 2007.

MUNANGA, Kabengelê. Prefácio. In: MOORE, Carlos. Racismo e sociedade: novas bases epistemológicas para entender o racismo. Belo Horizonte: Mazza, 2007. p. 15-19.

NOGUEIRA, Oracy. Preconceito de marca: as relações raciais em Itapetininga. São Paulo: USP, 1998.

PAIXÃO, Marcelo. Desenvolvimento econômico e as relações raciais no Brasil. In: GONÇALVES, Benjamim (Org.). O compromisso das empresas com a promoção da igualdade racial. São Paulo: Instituto Ethos, 2006.

PAIXÃO, Marcelo et al. Relatório anual das desigualdades raciais no Brasil: 2009-2010. Rio de Janeiro: Garamond, 2011.

PIOVESAN, Flávia. Ações afirmativas da perspectiva dos direitos humanos. Cadernos de Pesquisa, São Paulo, v. 35, n. 124, p. 43-55, jan./abr. 2005.

PROGRAMA DAS NAÇÕES UNIDAS PARA O DESENVOLVIMENTO (Pnud). Relatório de desenvolvimento humano: racismo, pobreza e violência. Brasília, 2005.

RIBEIRO, Darcy. O povo brasileiro: a formação e o sentido do Brasil. São Paulo: Companhia das Letras, 1996.

RIBEIRO, Darcy. Os brasileiros: 1 - Teoria do Brasil. Petrópolis: Vozes, 1987.

SANTOS, Boaventura de Souza. Reinventar a democracia: entre o pré-contratualismo e o pós-contratualismo. In: OLIVEIRA, Francisco; PAOLI, Maria Célia (Org.). Os sentidos da democracia: política do discurso e hegemonia global. Petrópolis: Vozes, 1999.

SANTOS, Hélio. A busca de um caminho para o Brasil: a trilha do círculo vicioso. 2. ed. São Paulo: Senac, 2003.

SANTOS, Hélio. O que Obama tem a ver com o Brasil? Veja, São Paulo, p. 88,12 nov. 2008. 
SANTOS, Helio et al. O preconceito contra minorias deve ser enfrentado com políticas compensatórias (ações afirmativas)? Folha de S. Paulo, São Paulo, Opinião, p. 3, 6 jul. 1996.

SELL, Sandro César. Ação afirmativa e democracia racial: uma introdução ao debate no Brasil. Florianópolis: Fundação Boiteux, 2002.

SILVA JUNIOR, Hédio. Direito de igualdade racial: aspectos constitucionais civis e penais - doutrina e jurisprudência. São Paulo: Juarez Oliveira, 2002.

SIRAQUE, Vanderlei. Controle social da função administrativa do Estado: possibilidades e limites na Constituição de 1988. 2. ed. São Paulo: Saraiva, 2009.

SKIDMORE, Thomas E. Ação afirmativa no Brasil? Reflexões de um brasilianista. In: SOUZA, Jessé (Org.). Multiculturalismo e racismo: uma comparação Brasil-Estados Unidos. Brasília: Ministério da Justiça, Secretaria Nacional de Direitos Humanos, 1997.

SKIDMORE, Thomas E. EUA birracial versus Brasil multirracial: o contraste é ainda válido? Novos Estudos Cebrap, São Paulo, n. 34, p. 49-62, 1992.

SOUZA NETO, Cláudio Pereira. A constitucionalidade das cotas étnicas e sociais nas universidades brasileiras: jurisprudência e parâmetros de decisão. In. ZONINNSEIN, Jonas; FERES JR., João (Org.). Ação afirmativa no ensino superior brasileiro. Belo Horizonte: UFMG; Rio de Janeiro: IUPERJ, 2008.

SOUZA, Marcilene Garcia de. Ações afirmativas e inclusão de negros por "cotas raciais" nos serviços públicos do Paraná. 2010. 457 f. Tese (Doutorado em Sociologia) - Universidade Estadual Paulista Júlio de Mesquita Filho, Araraquara, 2010.

TAKAHASHI, Fábio. País supera ricos no gasto em escola privada. Folha de S. Paulo, São Paulo, Folha Cotidiano, p. C1, 11 abr. 2011. Disponível em: <http://www1.folha.uol.com.br/fsp/cotidian/ff1104201101.htm>.

THEODORO, Mário (Org.). As políticas públicas e a desigualdade racial no Brasil: 120 anos após a Abolição. Brasília: IPEA, 2008.

WALTERS, Ronald. Racismo e ação afirmativa. In: SOUZA, Jessé (Org.). Multiculturalismo e racismo: uma comparação Brasil-Estados 
O subproduto social advindo das cotas raciais na educação

Unidos. Brasília: Ministério da Justiça, Secretaria Nacional de Direitos Humanos, 1997.

Hélio Santos, doutor em Administração pela Faculdade de Economia, Administração e Economia da Universidade de São Paulo, é professor titular do Mestrado Profissional em Desenvolvimento Humano e Responsabilidade Social da Fundação Visconde de Cairu, Salvador, Bahia, Brasil.

heliosan@uol.com.br

Marcilene Garcia de Souza, doutora em Sociologia pela Universidade Estadual Paulista Julio de Mesquita Filho (Unesp), é pesquisadora sobre relações sociais no Brasil do Instituto de Pesquisa da Afrodescendência (Ipad), Curitiba, Paraná, Brasil.

lenagsouza@yahoo.com.br

Karen Sasaki, doutora em Desenvolvimento Regional e Urbano pela Universidade Salvador (Unifacs), é professora titular do Mestrado Profissional em Desenvolvimento Humano e Responsabilidade Social da Fundação Visconde de Cairu (FVC) e professora e coordenadora de Desenvolvimento e Produção de Conteúdos (EAD) do Centro Universitário Jorge Amado (Unijorge), Salvador, Bahia, Brasil.

sasaki.karen@gmail.com

Recebido em 20 de abril de 2011.

Aprovado em $1^{\circ}$ de março de 2013. 